\title{
Researches Regarding the Spraying Uniformity of the TARAL 200 PITON TURBO machine
}

\author{
Andreea DIACONU*, Ioan ȚENU, Petru CÂRLESCU, Radu ROȘCA \\ ${ }^{1}$ Faculty ofAgriculture Sciences, University of Applied Life Science and Environment, Mihail Sadoveanu \\ Alley, no.3, Iași, Romania; \\ * corresponding author: andreea_diaconu_a@yahoo.com
}

Bulletin USAMV series Agriculture 72(1)/2015

Print ISSN 1843-5246; Electronic ISSN 1843-5386

DOI 10.15835/buasvmcn-agr: 10377

\begin{abstract}
Pest and disease control is an import technological link in order to maintain the health of the plantations and to obtain large amounts of high quality productions. Chemical control is the main method used in plant protection. Pesticides are applied on vegetation using sprayers specially designed for this purpose. Wear of the spray nozzle orifices, due to the hydroabrasion corrosion, leads to an uneven covering of the vegetation mass, with either untreated areas or overtreated ones. Before the start of each pest and disease control campaign, the nozzles should be tested in order to evaluate the uniformity of the liquid dispersion. In order to evaluate the dispersion uniformity for the TARAL 200 PITON TURBO spraying machine, a vertical stand was designed, fitted with 11 inclined troughs, each ending with a container for collecting the liquid. The tests were performed at different operating pressures, distances from the axis of the spraying machine, heights above the ground and fan speeds. The most uniform spray distribution was achieved for a height of $500 \mathrm{~mm}$, for fan speeds of 800 and $1400 \mathrm{rev} / \mathrm{min}$ and for all the operating pressures and distances. For the height of $700 \mathrm{~mm}$, uniformity was achieved for a speed of $1400 \mathrm{rev} / \mathrm{min}$, for all operating pressures and for the distances of 1700, 1900 and $2100 \mathrm{~mm}$.
\end{abstract}

Keywords: nozzle sprayers, pesticides, plant treatment, spraying, uniformity.

\section{INTRODUCTION}

Pest and disease control in vineyards is one of the most important technological links to obtain high yields of grapes. Diseases and pests can cause significant economic losses. If pesticide treatments are not applied efficiently and in time, production can be completely lost (Berca, 2001; Tenu et al., 2013).

The spraying equipment should be verified periodically in order to ensure an adequate treatment from the point of view of its efficiency and in terms of protecting the environment (Nagy et al., 2006). A correct application of the phytosanitary treatments, with high quality operating indices, leads to the decrease of production losses, of the amount of pesticides used and of the environmental pollution (Nagy and Coța, 2007).
In time, the nozzles wear out due to corrosive action of pesticides and spraying and their orifices are decalibrated. Thus, there is a rigorous control flow achieved. For this reason, it is necessary that before each campaign to combat pests and diseases, to determine the uniformity of the spray nozzle (Neghiu, 2008).

The purpose of this study was to determine the flow distribution through the spray nozzles for the TARAL 200 PITON TURBO spraying machine.

\section{MATERIALS AND METHODS}

In order to evaluate the spray distribution uniformity for the TARAL 200 PITON TURBO machine, used for pest and disease control in intensive vineyards and orchards, a test rig was designed and built. The rig has a vertical panel fabricated from polycarbonate, with a thickness of 
$10 \mathrm{~mm}$, a length of $1500 \mathrm{~mm}$ and a width of 850 $\mathrm{mm}$. Eleven galvanized steel trays were placed on the panel; the trays were inclined at $5^{\circ}$ and placed at $100 \mathrm{~mm}$ distance from each other. Each chute

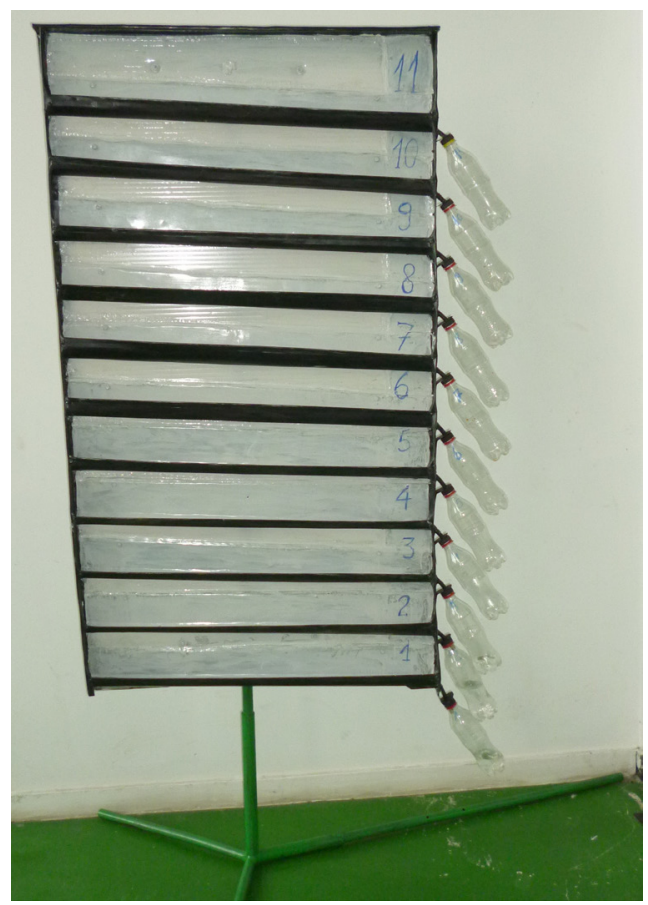

Fig. 1. Test rig for evaluating the uniformity of the spray nozzles flow distribution, for the TARAL 200 PITON TURBO machine.

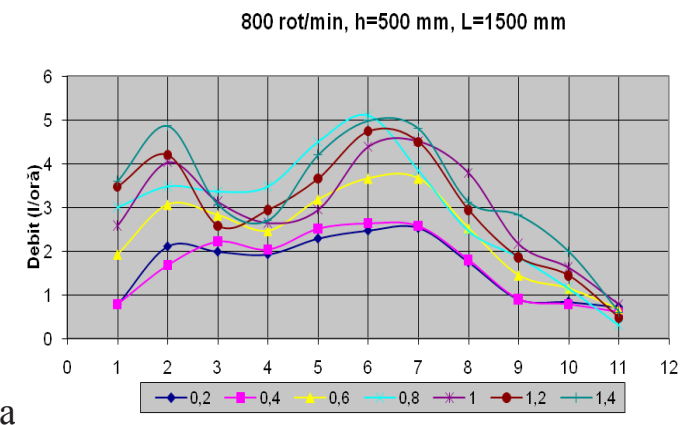

$800 \mathrm{rot} / \mathrm{min}, \mathrm{h}=500 \mathrm{~mm}, \mathrm{~L}=1900 \mathrm{~mm}$

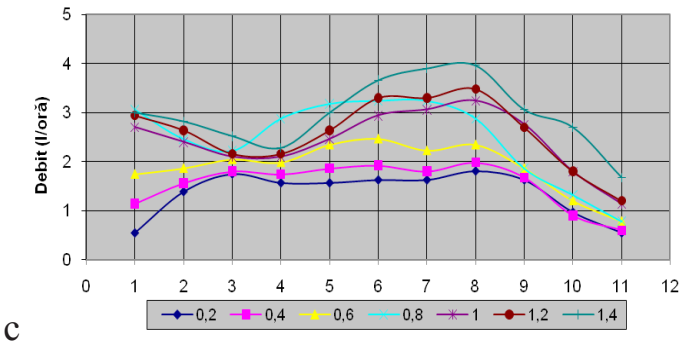

has a container at its end in order to measure the quantity of retained solution (Fig. 1).

The liquid distribution uniformity along the operating height of the machine $U_{d}(\%)$ must be higher than $85 \%$ and is calculated with Eq.(1):

$$
\mathrm{U}_{\mathrm{d}}=\left[1-\frac{\sqrt{\frac{\sum_{\mathrm{i}=1}^{\mathrm{i}=\mathrm{n}}\left(\mathrm{q}_{\mathrm{i}}-\mathrm{q}_{\mathrm{m}}\right)^{2}}{\mathrm{n}(\mathrm{n}-1)}}}{\mathrm{q}_{\mathrm{m}}}\right] \cdot 100
$$

Where $q_{i}$ - the flow collected by each tray;

$$
\begin{gathered}
q_{m} \text { - the average flow rate; } \\
n \text { - number of chutes. }
\end{gathered}
$$

\section{RESULTS AND DISCUSSION}

In order to evaluate the spraying uniformity of the TARAL 200 PITON TURBO machine laboratory tests were performed using the volumetric method, the solution collected during two minutes in each tray being measured with a graduated cylinder. The tests were performed for different heights of the test rig above the ground (500 to $700 \mathrm{~mm}$ ), different distances of the rig from the axis of the

$800 \mathrm{rot} / \mathrm{min}, \mathrm{h}=500 \mathrm{~mm}, \mathrm{~L}=1700 \mathrm{~mm}$

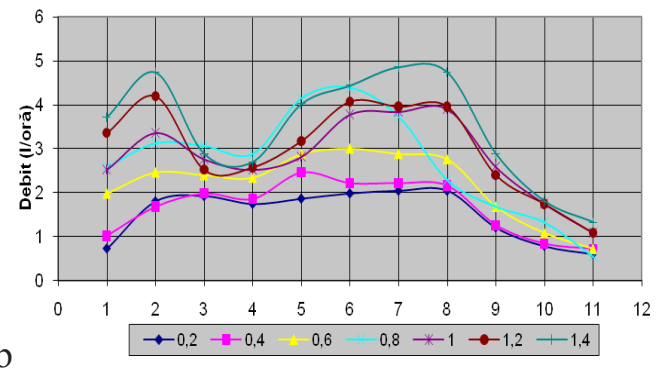

$800 \mathrm{rot} / \mathrm{min}, \mathrm{h}=500 \mathrm{~mm}, \mathrm{~L}=2100 \mathrm{~mm}$

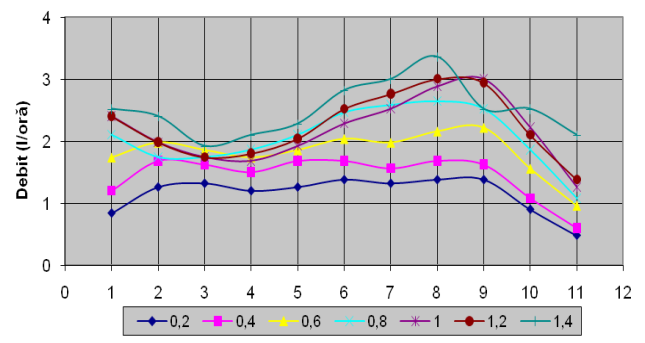

Fig. 2. Spraying uniformity of TARAL 200 PITON TURBO, depending on the operating pressure, at $800 \mathrm{rev} / \mathrm{min}$ fan speed, $500 \mathrm{~mm}$ rig height and distances of:(a) 1500; (b) 1700; (c) 1900; (d) $2100 \mathrm{~mm}$. 


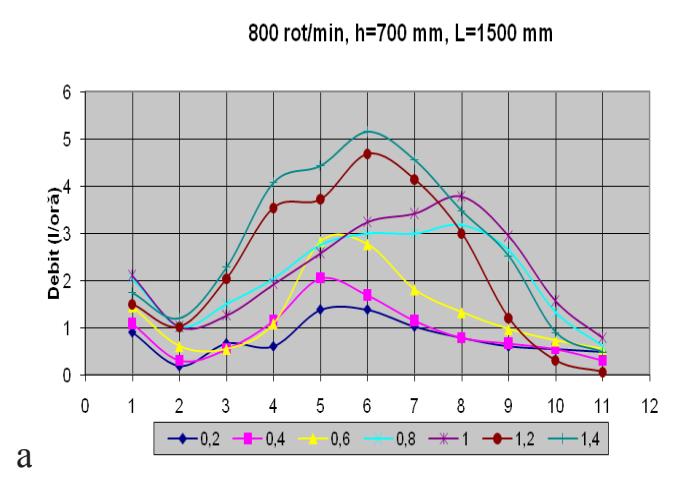

$800 \mathrm{rot} / \mathrm{min}, \mathrm{h}=700 \mathrm{~mm}, \mathrm{~L}=1900 \mathrm{~mm}$

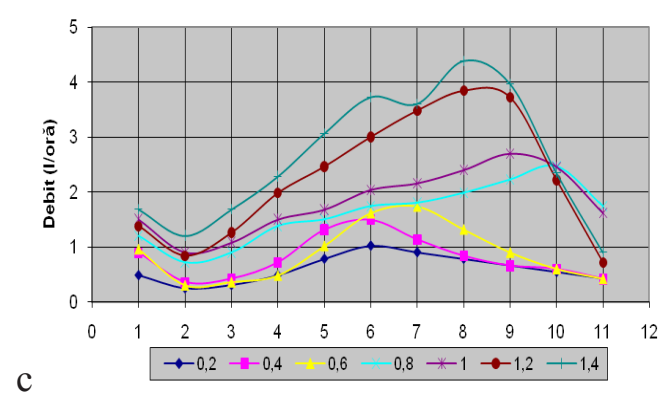

$800 \mathrm{rot} / \mathrm{min}, \mathrm{h}=700 \mathrm{~mm}, \mathrm{~L}=1700 \mathrm{~mm}$

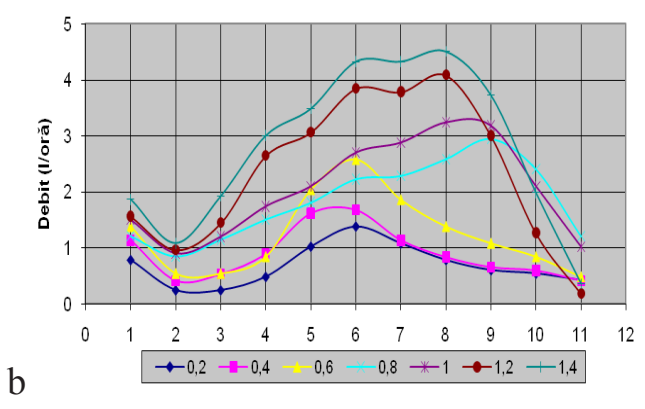

$800 \mathrm{rot} / \mathrm{min}, \mathrm{h}=700 \mathrm{~mm}, \mathrm{~L}=2100 \mathrm{~mm}$

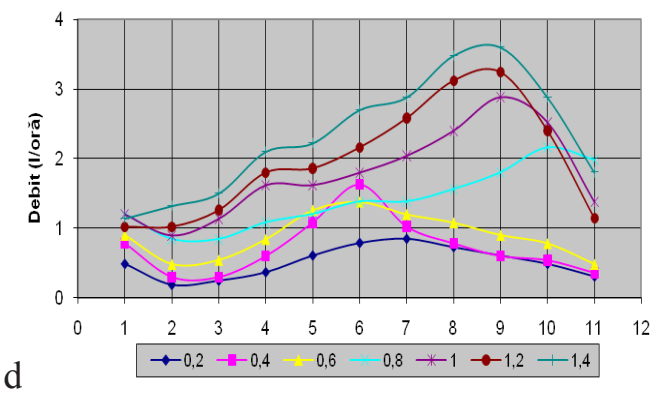

Fig. 3. Spraying uniformity of TARAL 200 PITON TURBO, depending on the operating pressure, at $800 \mathrm{rev} / \mathrm{min}$ fan speed, $700 \mathrm{~mm}$ rig height and distances of:(a) 1500; (b) 1700; (c) 1900; (d) $2100 \mathrm{~mm}$.

spraying machine $(1500,1700,1900$ and 2100 $\mathrm{mm})$, different fan speeds $(800,1100$ and 1400 $\mathrm{rev} / \mathrm{min})$ and several operating pressures $(0.2$, $0.4,0.6,0.8,1,0,1.2$ and $1.4 \mathrm{MPa}$ ).

With the increase of the working pressure and because to the higher turbulence, the distribution uniformity is affected, the best uniformities being achieved for the following operating pressures: $0.2,0.4$ and $0.6 \mathrm{MPa}$. For a fan speed of $800 \mathrm{rev} /$ min, with the rig placed at a height of $500 \mathrm{~mm}$ and at 1500 and $1700 \mathrm{~mm}$ distance from the machine axis, trays 1, 2, 6, 7 and 8 collected higher quantities of solution, while the lowest amounts were collected in trays 10 and 11 . For the distances of 1900 and $2100 \mathrm{~mm}$ trays 7, 8 and 9 collected the higher quantitities, while lower amounts of liquid were colected into trays 1, 2, 3 and 4 (Fig. 2).

With the increase of the mounting height to $700 \mathrm{~mm}$, for the same speed of the fan, it was found that, for the distances of 1500 and $1700 \mathrm{~mm}$, trays 6, 7 and 8 collected higher quantities; for the distance of 1900 and $2100 \mathrm{~mm}$, the maximum amount of collected liquid moved towards the trays 8, 9 and 10 (Fig. 3). This behavior is due to the fact that the spray beam moves when increasing the height and the distance from the panel.

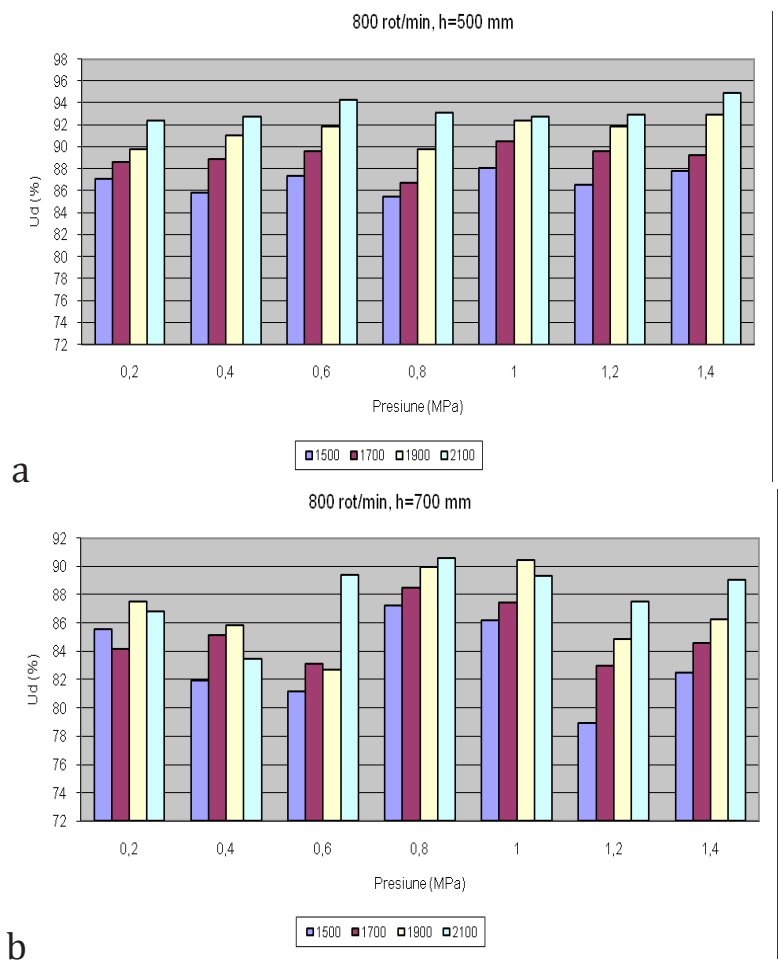

Fig. 4. $U_{d}(\%)$ depending on the operating pressure and the distance from the machine axis $(800 \mathrm{rev} /$ min): (a) height $500 \mathrm{~mm}$; (b) height $700 \mathrm{~mm}$. 
For a fan speed of $800 \mathrm{rev} / \mathrm{min}$, with the rig placed at a height of $500 \mathrm{~mm}$, the distribution uniformity index was higher than $85 \%$ for all the operating pressures and distances (Fig. 4a).

When the rig was placed at a height of $700 \mathrm{~mm}$ above the ground the values of the distribution uniformity index were higher than $85 \%$ for the following test conditions: pressures of 0.20 .8 and $1.0 \mathrm{MPa}$, distances of 1500,1700 and $1900 \mathrm{~mm}$; for the distance of $2100 \mathrm{~mm}$ a value lower than $85 \%$ was recorded at an operating pressure of 0.4 MPa (Fig. 4b).

The results for the fan speed of $1100 \mathrm{rev} / \mathrm{min}$ were similar to the ones obtained for the speed of $800 \mathrm{rev} / \mathrm{min}$ : as the distance increased from 1500 to $2100 \mathrm{~mm}$, the maximum flow moved from the lower part of the panel towards its upper part). Flow uniformity was achieved only for pressures between 0.6 and $0.8 \mathrm{MPa}$ and a distance of 1900 mm (Fig. 5).

Increasing the height above the ground to 700 $\mathrm{mm}$ resulted in higher flow rates being recorded in the lower part of the rig (trays 1,2,3) and towards its middle (trays 5 and 6), for all the tested distances (Fig. 6).

For a fan speed of $1100 \mathrm{rev} / \mathrm{min}$ and the height of $500 \mathrm{~mm}$, values of the distribution uniformity index higher than $85 \%$ were recorded for the following operating pressures: $0.4 ; 1.0$; 1.2 to $1.4 \mathrm{MPa}$ and for all the distances taken into account; when the pressure was set to $0.8 \mathrm{MPa}$ the distribution uniformity index recorded values below $85 \%$ for all the variants. With the operating pressure set to 0.2 and $0.6 \mathrm{MPa}$ the recorde uniformity was above $85 \%$ for the distances between 1700 and $2100 \mathrm{~mm}$ (Fig. 7a).

When the rig was placed at a height of $700 \mathrm{~mm}$

$U_{d}(\%)$ recorded values higher than $85 \%$ only for the pressures of $0.4,1.2$ and $1.4 \mathrm{MPa}$; for all the other pressures values below $85 \%$ were recorded for all the distances considered (Fig. 7b).

Fig. 8 presents the results recorded for the fan speed of $1400 \mathrm{rev} / \mathrm{min}$. For all the distances taken into account the lower area of the panel (trays 1,2 and 3 ) recorded higher flow values, the quantities being diminished towards the upper area of the panel. Higher uniformities were achieved for the pressures of 0.2, 0.4 and 0.6 MPa (Fig. 10).

Similar results were obtained when the pannel was placed at $700 \mathrm{~mm}$ above the ground, larger quantities of liquid being collected in the lower part of the panel and lower quantities in the upper part (Fig. 9).
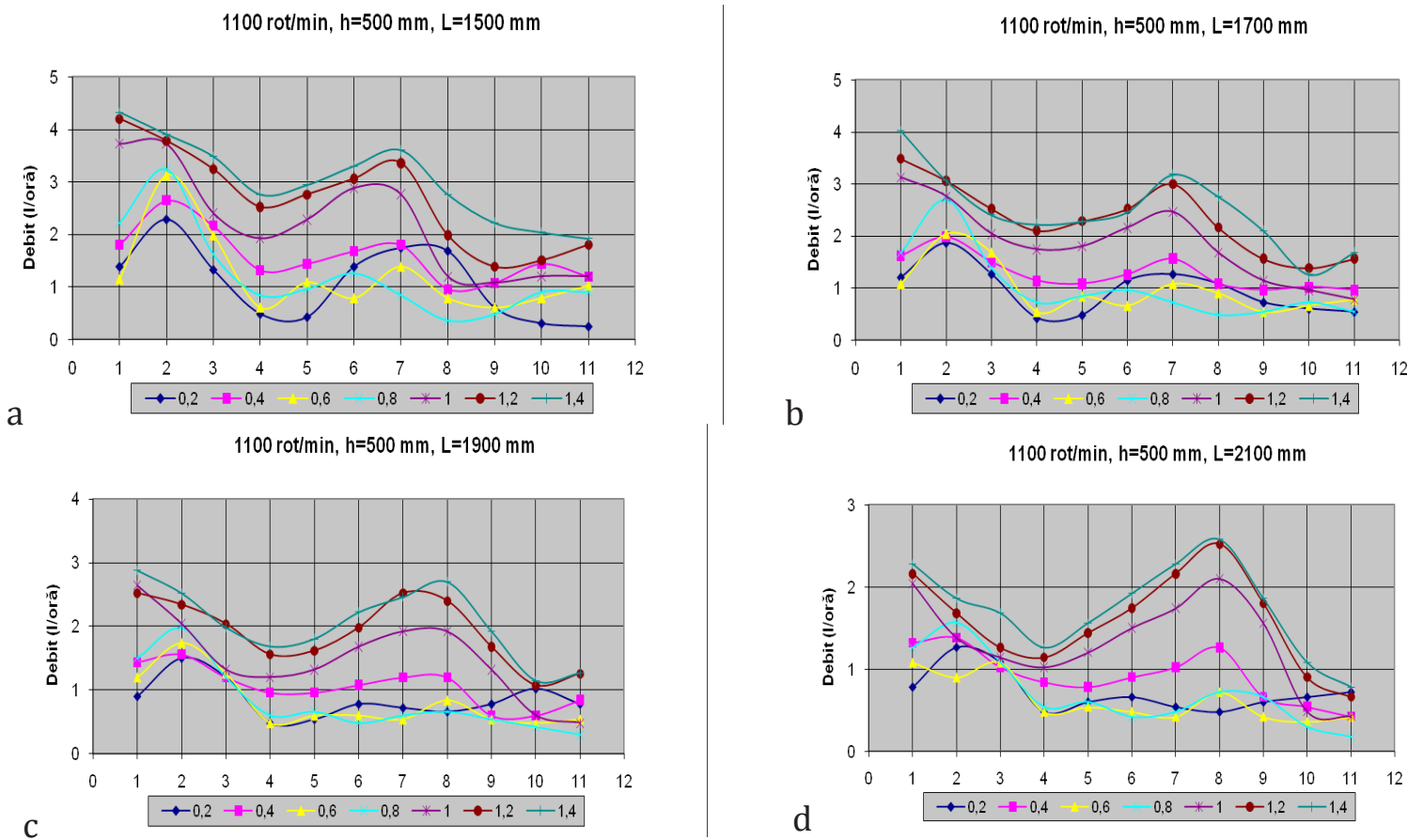

Fig. 5. Spraying uniformity of TARAL 200 PITON TURBO, depending on the operating pressure, at $1100 \mathrm{rev} / \mathrm{min}$ fan speed, $500 \mathrm{~mm}$ rig height and distances of: (a) 1500; (b) 1700; (c) 1900; (d) $2100 \mathrm{~mm}$. 
For the fan speed of $1400 \mathrm{rev} / \mathrm{min}$ and the height of $500 \mathrm{~mm}$ all the values of the distribution uniformity index were above the $85 \%$ limit (Fig. 10a).

When the panel was placed at a height of 700 $\mathrm{mm}$, most of the values of the $U_{d}(\%)$ index were higher than 85\%; exceptions were recorded for the $1500 \mathrm{~mm}$ distance and the pressures of 0.6 and $0.8 \mathrm{MPa}$ (Fig. 10b).

\section{CONCLUSION}

- The results of researches performed in laboratory conditions regarding the spraying uniformity of the TARAL 200 PITON TURBO machine led to the following conclusions:

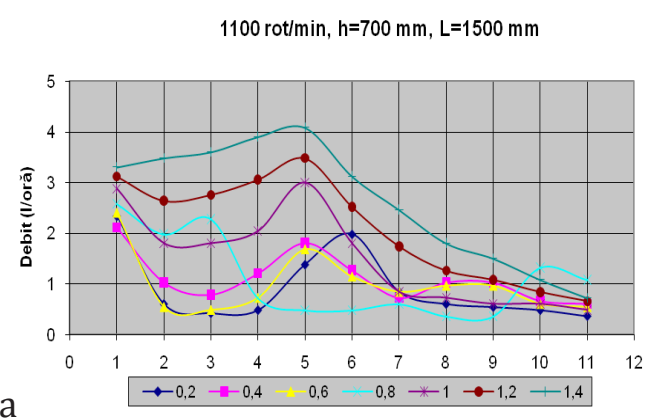

$1100 \mathrm{rot} / \mathrm{min}, \mathrm{h}=700 \mathrm{~mm}, \mathrm{~L}=1900 \mathrm{~mm}$

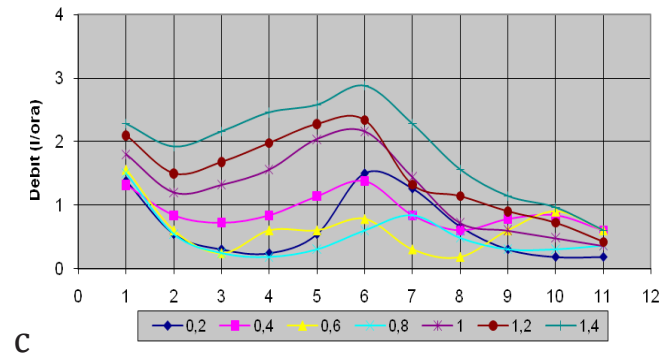

- the spraying machine fulfills the conditions referring to a uniform and efficient spraying;

- for a fan speed of $1400 \mathrm{rev} / \mathrm{min}$ the uniformity achieved was higher than $85 \%$ in all the tested variants, except for the following: height of $700 \mathrm{~mm}$, distance of $1500 \mathrm{~mm}$, pressures of 0.6 and $0.8 \mathrm{MPa}$;

- for a fan speed of $800 \mathrm{rev} / \mathrm{min}$ values over $85 \%$ were recorded only when the panel was placed at a height of $500 \mathrm{~mm}$;

- for a fan speed of $1100 \mathrm{rev} / \mathrm{min} U_{d}(\%)$ recorded values higher than $85 \%$ at all distances, when the operating pressure was set to $0.4,1.2$ and $1.4 \mathrm{MPa}$, with the panel placed at a height of $700 \mathrm{~mm}$; for the height
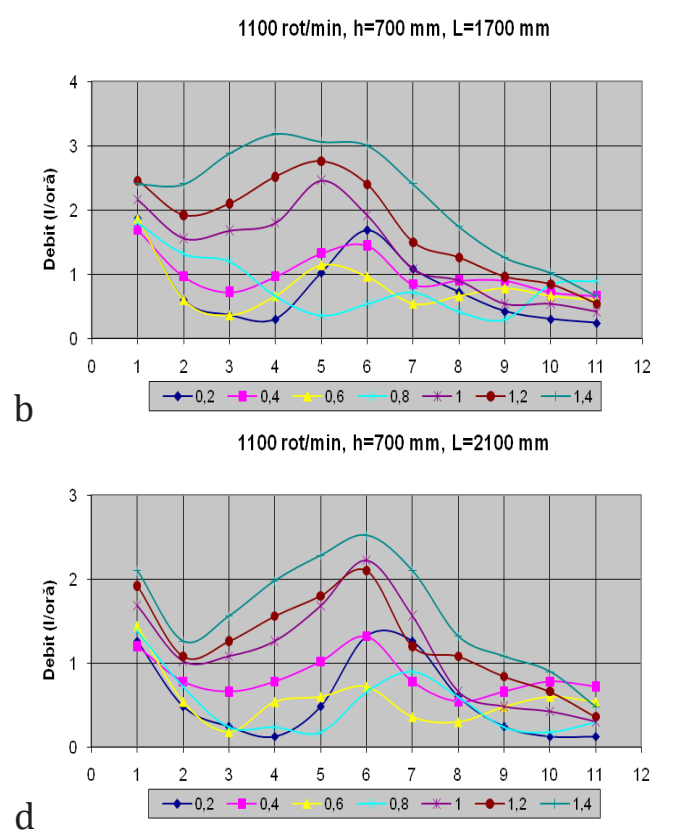

Fig. 6. Spraying uniformity of TARAL 200 PITON TURBO, depending on the operating pressure, at $1100 \mathrm{rev} / \mathrm{min}$ fan speed, $700 \mathrm{~mm}$ rig height and distances of: (a) 1500; (b) 1700; (c) 1900; (d) $2100 \mathrm{~mm}$.
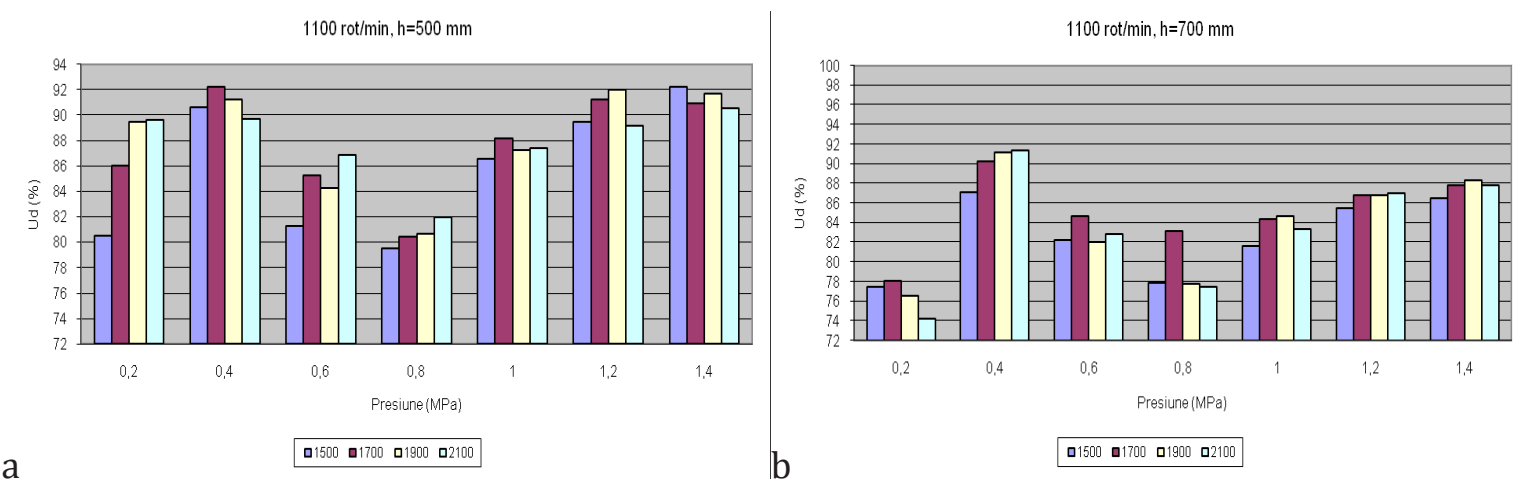

Fig. 7. $U_{d}(\%)$ depending on the operating pressure and the distance from the machine axis $(1100$ $\mathrm{rev} / \mathrm{min}$ ): (a) height $500 \mathrm{~mm}$; (b) height $700 \mathrm{~mm}$. 
$1400 \mathrm{rot} / \mathrm{min}, \mathrm{h}=500 \mathrm{~mm}, \mathrm{~L}=1500 \mathrm{~mm}$

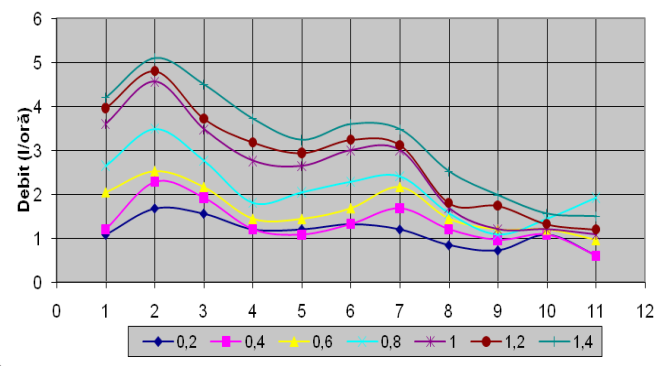

$1400 \mathrm{rot} / \mathrm{min}, \mathrm{h}=500 \mathrm{~mm}, \mathrm{~L}=1900 \mathrm{~mm}$

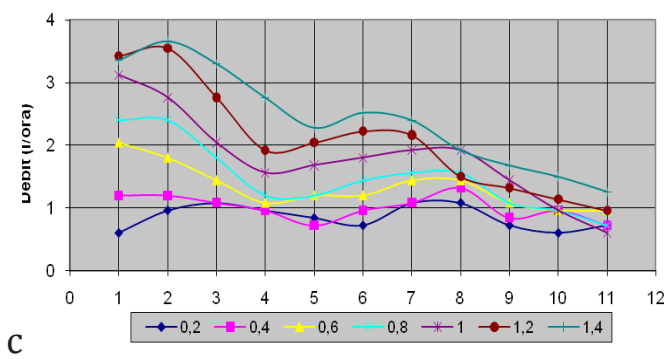

$1400 \mathrm{rot} / \mathrm{min}, \mathrm{h}=500 \mathrm{~mm}, \mathrm{~L}=1700 \mathrm{~mm}$

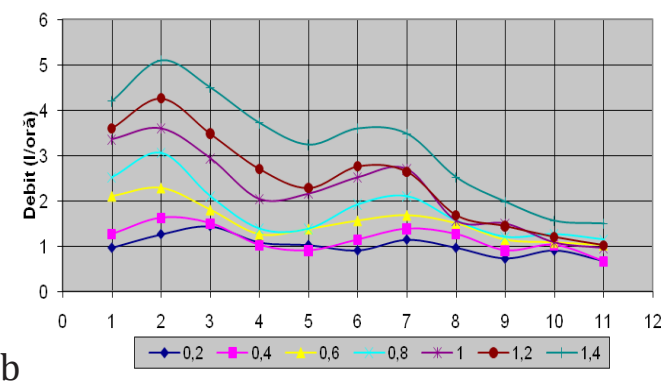

$1400 \mathrm{rot} / \mathrm{min}, \mathrm{h}=500 \mathrm{~mm}, \mathrm{~L}=2100 \mathrm{~mm}$

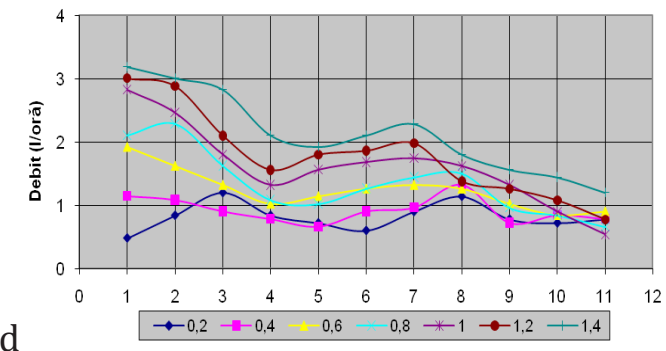

Fig. 8. Spraying uniformity of TARAL 200 PITON TURBO, depending on the operating pressure, at $1400 \mathrm{rev} / \mathrm{min}$ fan speed, $500 \mathrm{~mm}$ rig height and distances of: (a) 1500; (b) 1700; (c) 1900; (d) $2100 \mathrm{~mm}$.

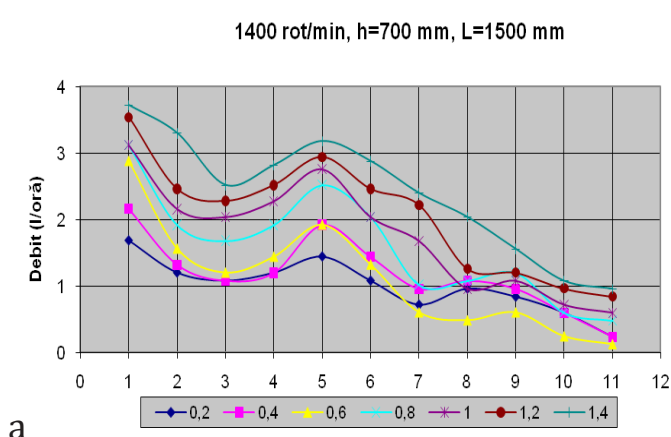

$1400 \mathrm{rot} / \mathrm{min}, \mathrm{h}=700 \mathrm{~mm}, \mathrm{~L}=1900 \mathrm{~mm}$

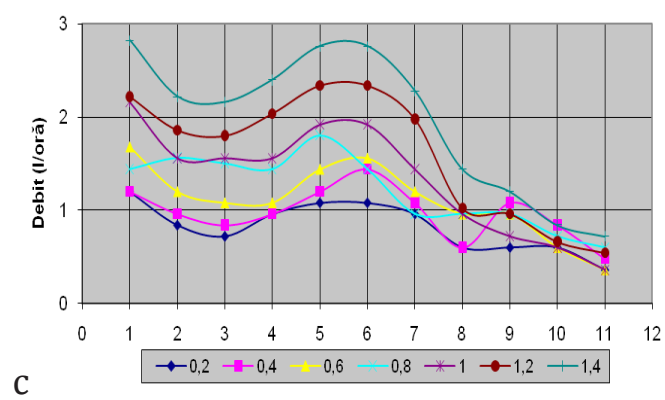

$1400 \mathrm{rot} / \mathrm{min}, \mathrm{h}=700 \mathrm{~mm}, \mathrm{~L}=1700 \mathrm{~mm}$
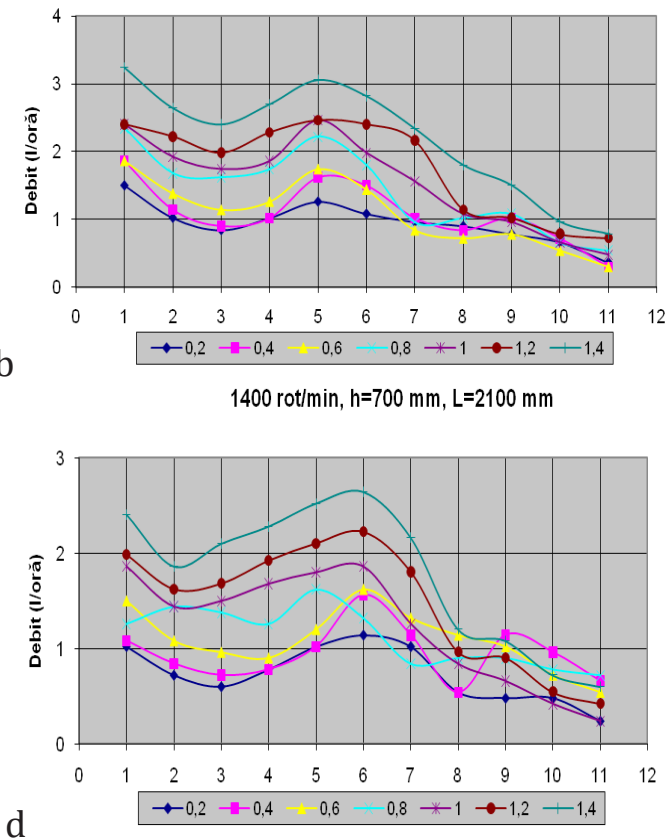

Fig. 9. Spraying uniformity of TARAL 200 PITON TURBO, depending on the operating pressure, at $1400 \mathrm{rev} / \mathrm{min}$ fan speed, $700 \mathrm{~mm}$ rig height and distances of: (a) 1500; (b) 1700; (c) 1900; (d) $2100 \mathrm{~mm}$. 

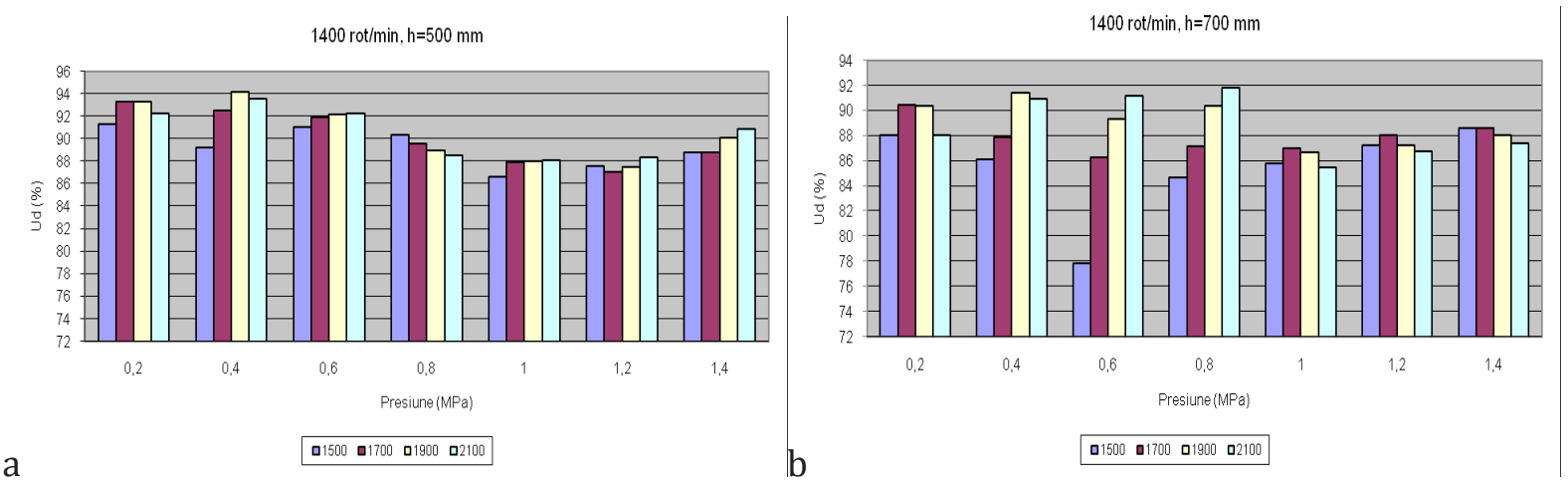

Fig. 10. $U_{d}(\%)$ depending on the operating pressure and the distance from the machine axis $(1400$ $\mathrm{rev} / \mathrm{min}$ ): (a) height $500 \mathrm{~mm}$; (b) height $700 \mathrm{~mm}$.

of $500 \mathrm{~mm}$ the requirements regarding the spraying uniformity were achieved only for the operating pressure of $1.0 \mathrm{MPa}$;

- in order to obtain higher quantities of liquid distributed in the central area of the panel the distance between the pannel and the machine axis should be of 1500 and $1700 \mathrm{~mm}$ when it is placed at $500 \mathrm{~mm}$ above the ground; for a height of $700 \mathrm{~mm}$ the optimum distance is of $1900 \mathrm{~mm}$;

- the preferred height of the rig above the ground is $500 \mathrm{~mm}$ in order to achieve a high quality of the plant treatment;

- $\quad$ spraying uniformity was achieved for the operating pressures of $0.2 ; 0.4 \mathrm{MPa}, 0.6 \mathrm{MPa}$ and $0.8 \mathrm{MPa}$;

- the nozzles that equip the TARAL 200 PITON TURBO spraying machine ensure the distribution uniformity.

Acknowledgments. This paper was published under the frame of European Social Fund, Human Resources Development Operational Programme 2007-2013, project no. POSDRU/159/1.5/S/ 132765.

\section{REFERENCES}

1. Berca M (2001). Agriculture in transition. Studies and articles (1998-2001). Publisher Ceres, Bucharest.

2. Nagy EM, Coța C (2007). Contributions to verify alignment equipment for the treatment plant in Romania to UE, Scientific Papers. Vol. 50, Series Agronomy.

3. Nagy EM, Coța C. Roman M, Fodorean G (2006). Ensure appropriate management of pesticides by accurate assessment of the characteristics of equipment for phytosanitary treatments in vineyards and orchards. Agriculture - Science and Practice, No. 1-2:57-58.

4. Neghiu L (2008). Horticultural machinery and equipment,Vol. I, Publisher Risoprint, Cluj-Napoca.

5. Țenu I, Diaconu A, Roșca R (2013). Equipment to reduce soil pollution by pesticides in pest and disease control in vineyards, Vol. 56, No. 1, Scientific Papers, Series Agronomy, Publisher „Ion Ionescu de la Brad”, Iasi. 